\title{
INVESTIGATION OF THE EVOLUTION OF HYDROPHOBICITY AND WETTABILITY OF PAPER IN MULTI-COLOR PRINTING PROCESS
}

\author{
CEM AYDEMIR, ${ }^{*}$ ARIF KARADEMIR, ${ }^{* *}$ SAMI IMAMOĞLU, ${ }^{* *}$ BILGE NAZLI ALTAY, ${ }^{* * *}$ \\ PAUL D. FLEMING ${ }^{* * *}$ and DOGAN TUTAK ${ }^{*}$ \\ *Printing Technologies Department, School of Applied Sciences, Marmara University, \\ 34722 Istanbul, Turkey \\ *** Department of Forest Industry Engineering, Faculty of Forestry, Bursa Technical University, 16310 \\ Bursa, Turkey \\ **** Department of Chemical and Paper Engineering, Western Michigan University, \\ Kalamazoo 49008-5462 MI, USA \\ $₫$ Corresponding author: Cem Aydemir, cemaydemir@marmara.edu.tr
}

Received January 2, 2019

One of the keys to improving print quality is to experimentally characterize the paper surface, structure and printability to obtain quality control mechanisms. In multi-color prints, determining the differences in the acceptance of the next color ink by the surface of the paper or the ink film that was previously printed is important for print quality. The criteria, such as ink setting, adhesion, color, gloss and density, in the printing process, depend on the wettability and absorbency of the paper. The surface structure of the paper is the most important factor in determining the hydrophobic properties. In this study, wetting and absorption dynamics of the printed partially hydrophobized paper surface were investigated. The aim was to measure the effect of the printed ink film on the wetting (surface free energy) and liquid absorption behavior of the paper. Liquid absorption changes on printed/unprinted paper surfaces were measured by the sessile drop method, using a contact angle-measuring device. The surface energies of the papers were calculated and evaluated according to the surface contact angle of the droplet.

Keywords: paper surface, hydrophobicity, wettability, sessile drop method, printability

\section{INTRODUCTION}

In printing, the most important factor is to obtain the correct substrate and ink combination. ${ }^{1}$ The visual quality of print results is substantially based on the optimal level of ink merging with a substrate, particularly the drying and stabilization process of ink on the substrate. ${ }^{2}$ The mechanisms of ink absorption and setting on porous materials, such as paper, for all types of printing methods, determine the rate of printing and influence the final quality of the print. ${ }^{3}$ For this reason, detailed information on the behavior of paper-liquid for paper/board, ink manufacturers, and the printing industry is undoubtedly important. ${ }^{4}$

The properties of the paper surface play an important role in terms of ensuring the applicability and operability of printing, various converting and finishing processes. Paper surfaces have porous structures that are chemically and physically heterogeneous. ${ }^{5}$ Fiber properties, filler loading in the stock preparation process, the settings in pressing, calendering, the composition of coating formulation are among the main factors that greatly affect the surface roughness and permeability of paper. ${ }^{6,7}$ The structure and fiber characteristics of the surface determine the behavior of the liquid phase content of the ink on the paper during the printing process.

The liquid absorption ability of paper is based on the capillarity action. Papers and cartons act fairly like filters due to this feature. The porous capillary structure of the paper absorbs the solvent (water, mineral oils etc.) from the printed wet ink film and removes it from the resin and pigment. Thus, the solvents penetrate into the paper network (Fig. 1), while the resin and pigment form a hard-solid layer on the surface. ${ }^{8}$ 


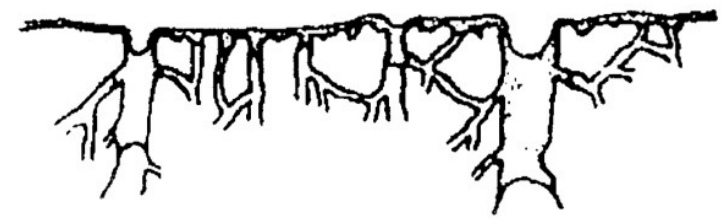

Figure 1: Schematic of the absorption and penetration of ink components into paper capillaries ${ }^{9}$

In sheet-fed offset printing, ink drying can be divided into two phases. The first phase is a separation of the low viscosity components from the ink film by absorption into the paper, which can be referred to as ink setting. The second phase is chemical drying through polymerization. ${ }^{10}$

In general, printed ink spreads and penetrates more into paper fibers when the paper surface is more permeable and rougher. The low absorption rate in the hydrophobic sheet is attributed to the high contact angle, the high absorption rate in the hydrophilic sheet is attributed to the low contact angle and the medium permeability coefficient.

The surface properties of the paper change after an ink film is printed. As a result, the changed surface could affect the finishing operations, such as varnishing, laminating, folding, gluing, cutting, binding and perforating. Therefore, it should be well known to what extent the ink film that is being printed one after the other affects the surface characteristics of papers.

In the multi-color printing process, cyan, magenta, yellow and black color inks are applied by different printing units. The penetration amount and rate of the inks into paper should be well known in terms of printing process and print quality. The degree of absorption of an ink into a substrate is of utmost importance in printing, since it is the contrast created between the ink and the substrate. Substrates with different degrees of liquid absorption result in different ink color results. ${ }^{11}$

The fiber structure, filler content and surface coating determine the absorption ability of paper substrates. Differences in coating formulations and filler contents, fiber and porous structure of papers cause differences in paper surfaces, in terms of resistance to liquids. Another factor affecting this resistance, which is usually ruled out, is the resistance of the previously printed ink film to absorb the subsequent ink film. Previously printed ink films make the paper surface more saturated compared to an unprinted paper surface. In the printing process, when one color is printed on another color, the absorption ability, surface energy and surface characteristics of the substrate change each time. This affects the acceptance, absorption and drying behaviors of subsequent ink colors.

The importance of the unprinted paper surface, or the first printed ink film, comes from the fact that they effect the drying of subsequent inks and print quality. Printing processes are greatly affected by surface properties, such as surface and interfacial tension, surface energy and adhesion. The absorbency, wettability and surface energy of the printing substrate should be well known in terms of ink adhesion, ink setting, drying process and high print quality to the printing substrate. Although there have been many publications on the surface properties and printability of polymer films to date, the absorbency, contact angle, wettability and surface energy changes on unprinted and printed paper surfaces and the effect of these changes on printability have not been evaluated. There is not enough research carried out on these issues. In this study, unprinted papers were experimentally compared to printed ones, using the sessile water droplet method. The results were associated with print quality and suggestions were proposed.

\section{EXPERIMENTAL}

\section{Materials and methods}

A mineral oil based sheet-fed offset printing ink conforming to ISO 2846-1:2006 standards was used for printing on $135 \mathrm{~g} / \mathrm{m}^{2}$ matte and gloss coated papers as a solid tone according to ISO12647-2:2013 standards. Coated papers were conditioned in accordance to DIN EN 20187 at $23{ }^{\circ} \mathrm{C} \pm 0.5{ }^{\circ} \mathrm{C}$ and $50 \% \pm 1.5 \%$ relative humidity for 24 hours before the printing trials.

The liquid absorption behavior, contact angle and surface energy values of the printed and unprinted papers were measured and analyzed by the sessile drop method, using a computer integrated DataPhysics device. The sessile drop was placed on printed and unprinted paper under constant experimental conditions and in equal volume. The volume change of 
the sessile water drop was both measured and photographed starting from the moment of the first contact with the substrates, using a CCD camera. The behavior of unprinted and printed papers was determined as a function of time. The drop shape was analyzed by image analysis software (SCA 20, Version 3.1.4), which was used to calculate the contact angle on the substrates.

In order to calculate the surface energies of the substrates, contact angle measurements were performed with water and dimethyl sulphoxide. Afterwards, surface energies were calculated according to the software-based Owens-Wendt (OW) equation. The differences between the printed and unprinted substrates were demonstrated and evaluated based on the liquid-solid contact angle, surface energy and liquid absorption.

\section{Surface properties of papers}

The roughness or smoothness of the paper is a very important feature for print quality. ${ }^{12}$ The surface profile of the test papers was measured according to TAPPI T555 om-99 with an L\&W PPS Roughness Tester. Air permeability values were measured with an L\&W Bendtsen Air Permeability Tester according to
TAPPI T460. The specular gloss of the coated papers was determined using a BYK Gardner Glossmeter (Sheen Instrument, U.K.) with $75^{\circ}\left(15^{\circ}\right.$ from the plane of paper) geometry according to TAPPI T 480 om-09. The specifications of gloss coated papers and matte coated papers are listed in Table 1.

\section{Printability properties and printing ink}

Print trials were done in accordance with ISO 12647-2:2013 standard on a Prüfbau Printability Tester under the optimal laboratory conditions. ${ }^{13}$ Print speed and print pressure were of $0.5 \mathrm{~m} / \mathrm{s}$ and $250 \mathrm{~N}$, respectively. A solid tone color was printed on 40x 198 $\mathrm{mm}$ print area. The mineral oil based sheet-fed offset printing ink (Michael Huber München Resista Cyan series), in agreement with ISO 2846-1:2006 standards, was used for the printing trials (Table 2).

The cyan ink film was measured with an X-Rite eXact $^{\mathrm{TM}}$ Portable Spectrophotometer (X-Rite Europe $\mathrm{GmbH}$, Regensdorf, Switzerland) with the settings of M0 (ISO 12647-2: D50 illuminant, $2^{\circ}$ observer and 0/45 geometry, white backing and without polarization filter) to track its coordinates at CIE $\mathrm{L}^{*}(54) \mathrm{a}^{*}(-36)$ b*(-49).

Table 1

Specifications of papers

\begin{tabular}{lcccc}
\hline Properties & Units & Standard & $\begin{array}{c}\text { Gloss } \\
\text { coated paper }\end{array}$ & $\begin{array}{c}\text { Matte } \\
\text { coated paper }\end{array}$ \\
\hline Basis weight & $\left(\mathrm{g} / \mathrm{m}^{2}\right)$ & ISO 536 & 135 & 135 \\
Thickness/Caliper & $\mu \mathrm{m}$ & Tappi T 411 & 103 & 109 \\
CIE-Whiteness, D65/10 & & ISO 11475 & 82.87 & 85.04 \\
Gloss (at 75 $)$ & $\%$ & Tappi T 480 & 79 & 31 \\
Roughness PPS (1.0) & $\mu \mathrm{m}$ & Tappi T 555 & 0.75 & 1.33 \\
Air permeability (Bendtsen) & $\mu \mathrm{m} /$ Pas & Tappi T 460 & 0.112 & 0.103 \\
\hline
\end{tabular}

Table 2

Properties of cyan printing ink

\begin{tabular}{lc}
\hline Parameters & Values \\
\hline Boiling point & $250{ }^{\circ} \mathrm{C}$ \\
Flash point & $>100^{\circ} \mathrm{C}$ \\
Ignition point & $200^{\circ} \mathrm{C}$ \\
Vapor pressure (at $\left.20^{\circ} \mathrm{C}\right)$ & $<0.1 \mathrm{hPa}$ \\
Density (at $\left.20^{\circ} \mathrm{C}\right)$ & $1.088 \mathrm{~g} / \mathrm{cm}^{3}$ \\
Solvent content & Organic solvents $<0.5 \%$ \\
& Water $<0.5 \%$ \\
\hline
\end{tabular}

\section{RESULTS AND DISCUSSION}

\section{Liquid absorption on print substrate surfaces}

The printability of a substrate lies in its aptitude to receive an ink film. Two additional important paper properties that are mentioned in conjunction with printability are the runnability of the surface and the liquid ink absorption behavior of the paper. This process is a function of various variables in the substrate structure, such as pores, fiber types, sizing and coating. ${ }^{14}$ In this study, the absorptivity (TAPPI T558) measurements of printed solid ink film surface and unprinted paper surface samples were performed by using DataPhysics Instruments $\mathrm{GmbH}$, Filderstadt, 
Germany, which has an electronic multipledosing system and a CCD video camera.

The experiment was done by placing a fresh doubly distilled water drop on the printed ink film and unprinted paper surfaces and measuring the dynamic drop volume. Sessile drop measurements were done on glass samples as well, to be able to compare the results with those for the coated papers. The measurements were repeated at least 10 times and mean values and standard deviations were determined.

Three different substrates were tested to reveal the interactions with water and the oil-based ink. The results were discussed in terms of the absorption behavior of unprinted and printed paper samples.
Three basic phenomena occurred during the interaction of the water droplet with the coated paper after the evaporation of water under the ambient conditions: (1) the absorption of water by the paper, (2) swelling of paper surface and (3) spreading of water on the paper surface (Figs. 25).

The ability to hold water, dimensional changes and strength changes upon wetting are some of the paper fiber properties of importance. Swelling is one of the most important mechanisms of paper that occur during the water-fiber interaction. ${ }^{15}$ In the study, the reaction of cellulose with water causes swelling of the fibers and a structural change. The swellability of cellulose fibers is an important feature to be considered in printing activities with liquid inks.

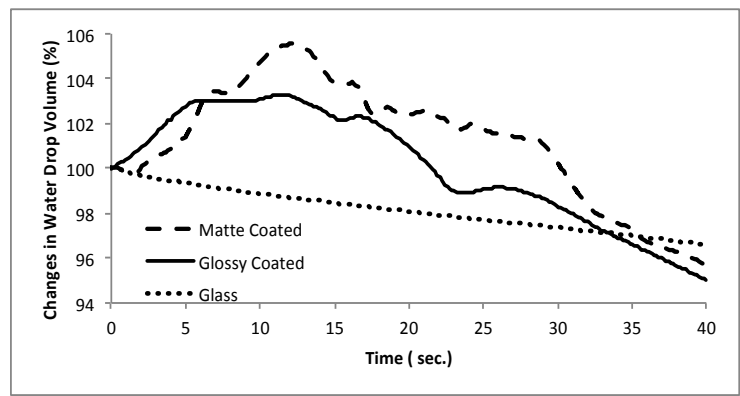

Figure 2: Water drop volume evolution on unprinted paper surfaces
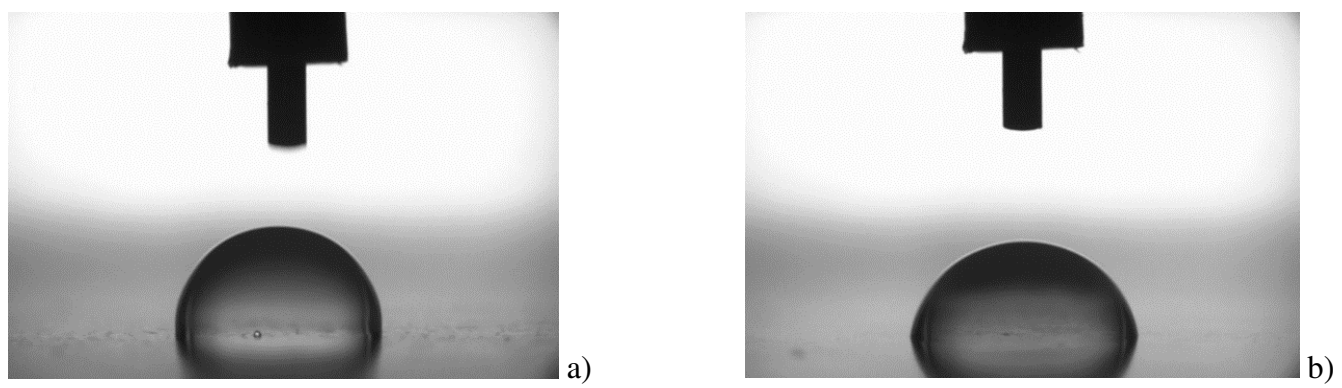

Figure 3: Water droplets on unprinted paper surfaces: (a) matte coated, (b) glossy coated surface

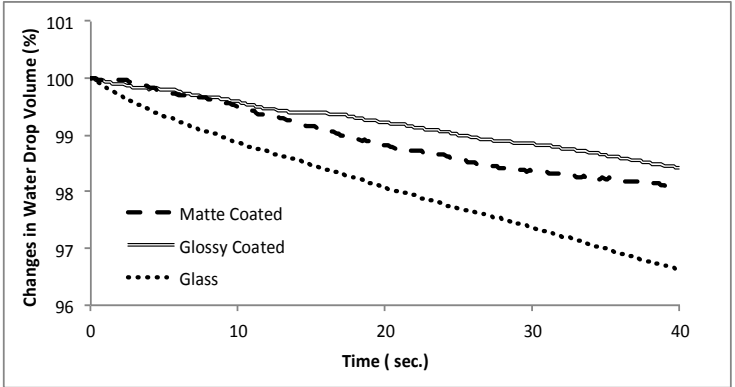

Figure 4: Water drop volume evolution on printed paper surfaces 

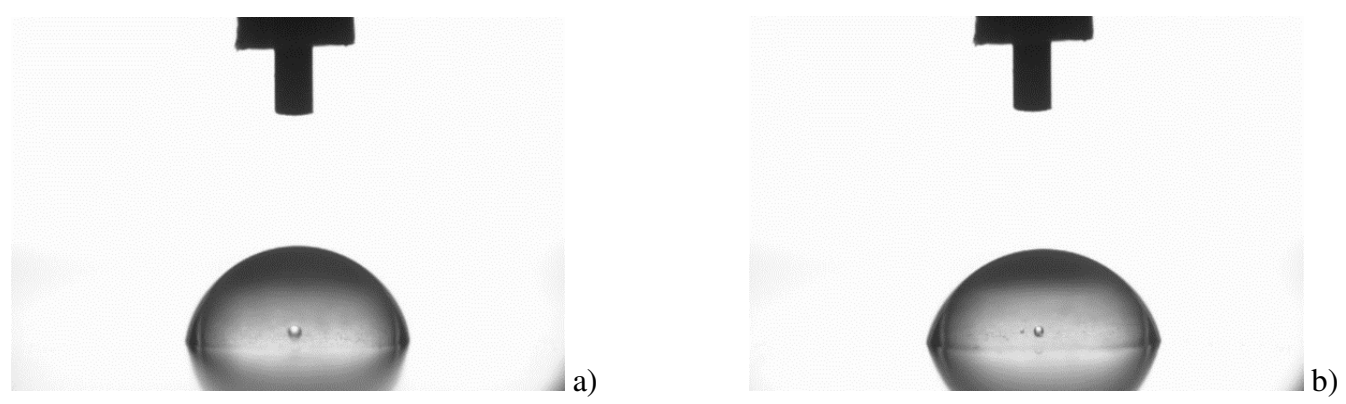

Figure 5: Water droplets on printed paper surfaces: (a) matte coated, (b) glossy coated surface

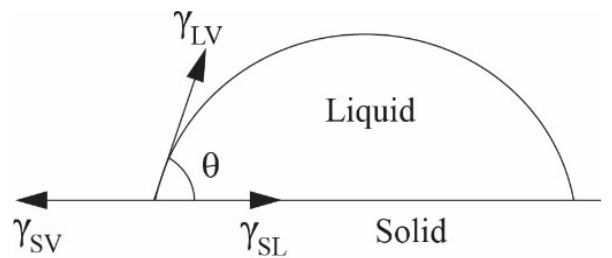

Figure 6: Contact angle of a liquid on a solid surface (contact angle $\left.<90^{\circ}\right)^{9,20}$

In the case of printed samples, swelling was not observed. The surface is more stable and resistant to the liquid absorption and hydroexpansion. Liquid absorption in the printed samples is not the same as in the unprinted samples because of the ink-filled porous structure. The printed surfaces have low liquid absorption ability when compared to the unprinted samples, because of the ink-filled paper surface. In other words, the oil-based ink film decreases the absorption ability of papers. This will affect the adhesion, gloss, reflection and drying process of the ink to be printed on the substrate.

\section{Contact angle characterization of print substrates}

Wettability, an important feature of the printing substrate, defines the degree to which a liquid diffuses into a solid surface and affects ink receptivity, coating, absorbency, adhesion and frictional properties in the printing process. ${ }^{16,17}$ The interaction between liquids and substrates can be characterized by the contact angle that the liquid forms on the substrate. ${ }^{18}$ Contact angle measurement showing the wetting performance of substrates is a conventional method for describing the hydrophobic or hydrophilic behavior of a material. This method is widely used to evaluate the wettability of cellulose-based surfaces and to judge their suitability for different applications. ${ }^{17}$
The characterization is performed by the liquid absorbing rate of porous bodies. ${ }^{19}$

When characterizing the absorptive capacity of papers for liquids, it is important to indicate the conditions, such as type of the liquid and the contact time. Liquids could penetrate into the pores of paper at a very fast rate; therefore, the contact angle must be identified from the initial set on the substrate as a function of time. The spreading of the water drop as a function of time explains and characterizes the dynamic wetting by the outermost surface layer of the wetted spot. ${ }^{20}$

The Dynamic Absorption Test (DAT) is commonly described as contact angle (Fig. 6) measurement using the sessile drop method. This angle is the internal angle between the substrate and the tangent at the point of contact between the liquid and the substrate. Young's equation defines the relationship between a contact angle and the surface energy forces from the interfacial tensions. ${ }^{20}$

At equilibrium, the three surface/interfacial tensions are related by the Young-Dupree equation $(1):{ }^{21}$

$\gamma_{\mathrm{sv}}=\gamma_{\mathrm{SL}}+\gamma_{\mathrm{LV}} \cos \theta$

where $\gamma_{\mathrm{SV}}=$ solid-vapor interaction, $\gamma_{\mathrm{SL}}=$ solidliquid interaction, $\gamma_{\mathrm{LV}}=$ liquid-vapor interaction.

To determine the wettability (surface free energy) of the paper sheets, the contact angles of 
the sessile drops were measured. Contact angle (CA) tests were carried out using DataPhysics OCA-20 contact angle equipment. Water was used as test liquid. When the starting points are

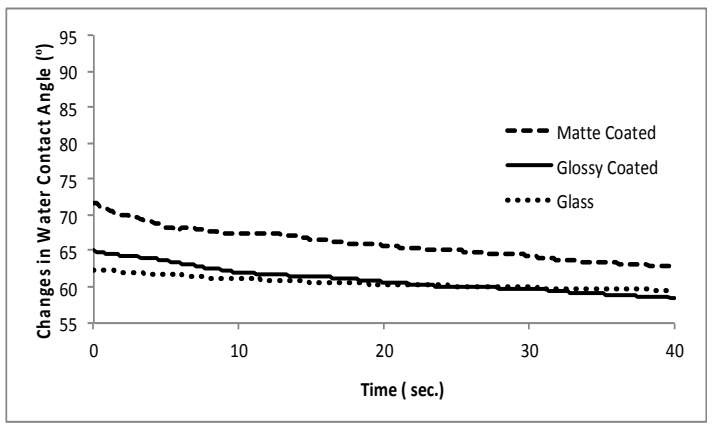

Figure 7: Evolution of the contact angle of the water drop on unprinted paper surfaces compared, the contact angles for unprinted glossy and matte coated papers are 65 and 72 degrees and 82 and 92 degrees for the printed ones (Figs. 7 and 8).

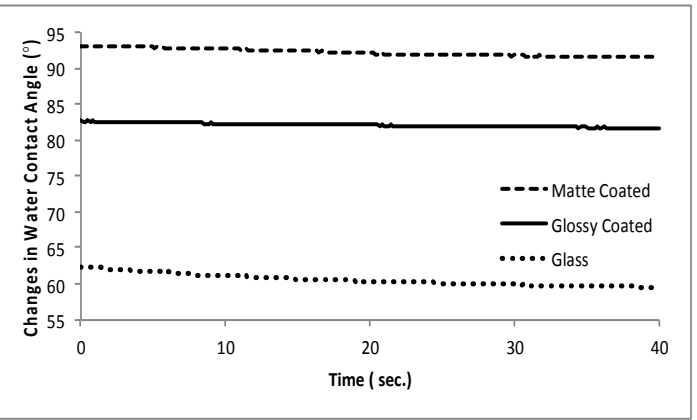

Figure 8: Evolution of the contact angle of the water drop on printed paper surfaces

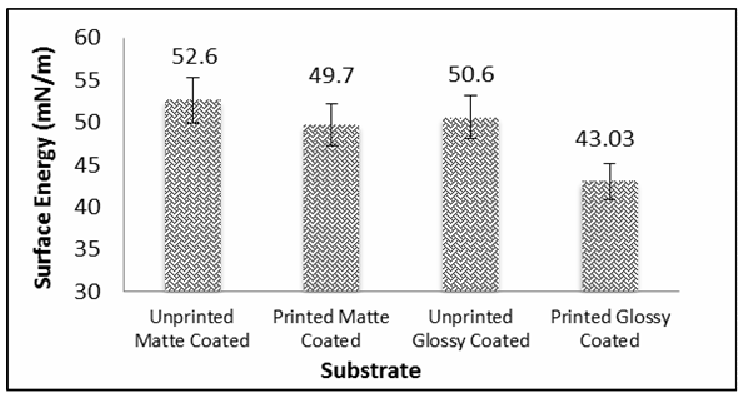

Figure 9: Surface energies of printed and unprinted paper surfaces

The contact angle of the water drops on the paper surfaces increased more in the printed papers than in the unprinted ones. Thus, it could be concluded that printed paper surfaces have greater water resistance than unprinted paper surfaces. Accordingly, since the acceptance of the color to be printed on printed and unprinted surfaces will be different, the sequence in which the colors (CMYK) are laid down can significantly alter the final printed result.

\section{Surface wetting characterization using contact angle measurements of substrates}

Contact angle, or the cosine of the contact angle, is often referred to as wetting of solids. This wetting is based on the surface tension of the liquid and the surface free energy of the solid, which are the major factors of capillary absorption. ${ }^{10}$ To ensure good printability, the surface tension of the ink should be lower than the surface energy of the substrate. The surface energy and especially the polarity of the surface govern the behavior of the paper in contact with another phase, e.g. printing inks, polymer films, lacquers. Determining the surface energy is therefore very important.

Surface energy is sensitive to the chemistry of the surface, the morphology and the presence of adsorbed materials. ${ }^{17}$ In this study, the contact angles required to calculate the surface energy were measured using two different liquids: water and dimethyl sulfoxide. The surface free energies of the printed and unprinted test samples were calculated according to the Owens-Wendt standard method for the contact of these two different liquids with the substrate surface. The Owens-Wendt equation (2) is one of the methods used to calculate the surface free energy of materials from contact angles. ${ }^{22}$

The Owens and Wendt geometric mean equation is the following:

$$
(1+\cos (\theta)) \gamma_{\mathrm{LV}}=2 \sqrt{ }\left(\gamma_{\mathrm{S}}{ }^{\mathrm{D}}{\gamma_{\mathrm{L}}}^{\mathrm{D}}\right)+2 \sqrt{ }\left(\gamma_{\mathrm{S}}{ }^{\mathrm{P}} \gamma_{\mathrm{L}}{ }^{\mathrm{P}}\right)
$$

The surface energy of offset ink printed samples was found to be lower than the unprinted paper samples. It was revealed that the surface 
energy of printed gloss coated papers decreased more than that of the printed matte coated papers.

Since low surface energy will adversely affect the bond strength of the ink to the substrate, it will be a disadvantage, especially for multicolor and dense prints requiring good ink adhesion. This will reduce the acceptance of other colors to be printed on the previous color in multicolor prints. Therefore, changing the color order in multi-color printing (e.g. CMYK or MCYK) will result in color differences in the final print result. In addition, adhesion and lamination processes in post-print packaging production will be difficult, as each printed color film reduces the surface energy of the substrate.

\section{CONCLUSION}

The present study allowed drawing the following conclusions.

Printed or unprinted coated paper surfaces affect the penetration time of the liquid. Unlike the case of the unprinted paper surface, the printed ink film behaves almost like a glass surface during the printing of a subsequent ink film, in terms of the absorption of the liquid phase of the inks. In other words, the behavior of printed paper surfaces is similar to that of the glass surface. This situation affects the drying process of the printed paper surface, as well as the adhesion and trapping of the ink, compared to the situation of unprinted paper. Therefore, in order to prevent adverse effects on the final printing results in multicolor printing, this change on the paper surface should be taken into consideration and the CMYK color order should be determined correctly.

Paper fibers absorb the liquid phase of the ink and get blocked up. This makes the paper saturated with liquids and gives it more hydrophobic properties. The gain in hydrophobicity increases the contact angle between the water and the paper, therefore the wettability of the paper decreases. This should be also taken into account in terms of the amount of ink to be consumed, the ink density value and drying.

This study shows that the saturated paper surface has an effect on the liquid-solid contact angle and surface energy. This fact should be also considered in the processes of printing, lamination, bonding, overprint lacquers, finishing operations, packaging design and manufacture.

Printed papers are actually materials impregnated with inks, binders and various chemicals, depending on the printing system and the desired end-product properties. Such papers are also exposed to some degree of heat treatment during printing processes. For these reasons, printed papers are normally expected to take some more time at the stage of pulping during recycling. The reasons behind this phenomenon could be that most of the $\mathrm{OH}$ groups in hemicelluloses and celluloses are blocked with chemicals and the hornification effects of fibers caused by drying.

ACKNOWLEDGEMENTS: This work was supported by Marmara University, Commission of Scientific Research Project (M. U. BAPKO) under grant FEN-B-100615-0271.

\section{REFERENCES}

1 C. Aydemir and S. Yenidoğan, Journal of Graphic Engineering and Design, 9, 37 (2018), https://doi.org/10.1016/JGED-2018-1-037

2 A. Karademir, S. Yenidoğan, C. Aydemir and H. Kucuk, Int. J. Polym. Mater., 61, 357 (2012), https://doi.org/10.1080/00914037.2011.584231

3 H. Hamada, J. Imaging Sci. Technol., 53, 50201-1 (2009),

https://doi.org/10.2352/J.ImagingSci.Technol.2009.53. 5.050201

4 C. Aydemir, Int. J. Polym. Mater., 59, 387 (2010), https://doi.org/10.1080/00914030903538470

5 H. Aslannejad, H. Fathi, S. M. Hassanizadeh, A. Raoof and N. Tomozeiu, Chem. Eng. Sci., 191, 78 (2018), https://doi.org/10.1016/j.ces.2018.06.054

6 C. Aydemir, A. Karademir and S. İmamoğlu, Int. J. Polym. Mater., 59, $891 \quad$ (2010), https://doi.org/10.1080/00914037.2010.504154

7 H. K. Navaz, B. Markicevic, A. R. Zand, Y. Sikorski, E. Chan et al., J. Colloid. Interf. Sci., 325, 440 (2008), https://doi.org/10.1016/j.jcis.2008.04.078

8 S. Yenidoğan, C. Aydemir, A. Karademir and E. A. Kandırmaz, Cellulose Chem. Technol., 53, 325 (2019), http://www.cellulosechemtechnol.ro/pdf/CCT34(2019)/p.325-331.pdf

9 C. Aydemir and C. Özakhun, in "Matbaa Malzeme Bilimi”, ISBN: 978-975-400-314-7, Marmara University Publication, 2014, pp. 262-264, http://bt.ubyo.marmara.edu.tr/en/our-published-books/

10 G. Ström, in Procs. $13^{\text {th }}$ Fundamental Research Symposium, Cambridge, UK, September 11-16, 2005, pp. 1101-1137, http://www.ppfrs.org/

1 S. Thorman, G. Ström, A. Hagberg and P.- $\AA$. Johansson, Nord. Pulp Pap. Res. J., 27, 459 (2012), https://doi.org/10.3183/npprj-2012-27-02-p459-465

12 R. Xu, P. D. Fleming and A. Pekarovicova, J. Imaging Sci. Technol., 49, $660 \quad$ (2005), http://citeseerx.ist.psu.edu/viewdoc/download?doi=10. 1.1.308.4865\&rep=rep $1 \&$ type $=$ pdf 


\section{CEM AYDEMIR et al.}

13 ISO 12647-2:2013: Graphic technology - Process control for the production of half-tone colour separations, proof and production prints - Part 2: Offset lithographic processes, https://www.iso.org/standard/57833.html

14 R. Klein, M. Miletic, P. Cunnigbam, G. Meder and H. Grossman, J. Print Media Technol. Res., 1, 25 (2012), http://iarigai.com/publications/journals/1-2012/ 15 N. K. Bhardwaj, Cellulose Chem. Technol., 53, 113 (2019),

http://www.cellulosechemtechnol.ro/pdf/CCT12(2019)/p.113-120.pdf

16 C. Aydemir, S. Yenidoğan, A. Karademir and E. A. Kandirmaz, J. Appl. Biomater. Funct. Mater., 16, 137 (2018), https://doi.org/10.1177/2280800018764761

17 M. A. Hubbe, D. J. Gardner and W. Shen, BioResources, 10, $8657 \quad$ (2015), https://ojs.cnr.ncsu.edu/index.php/BioRes/article/view/ BioRes_10_4_Review_Hubbe_Contact_Angles_Wetta bility_Cellulosic_Surfaces/3966

18 C. Aydemir, S. Yenidoğan, A. Karademir and E. Arman, Mater. Manuf. Processes., 32, 1310 (2017), https://doi.org/10.1080/10426914.2017.1279323

19 E. Drioli, A. Criscuoli and E. Curcio, Int. J. Membrane Sci. Technol., 11, 40 (2006), https://doi.org/10.1016/S0927-5193(05)80003-8

20 B. C. Lim, N. L. Thomas and I. Sutherland, Prog. Org. Coat., 62, 123 (2007), https://doi.org/10.1016/j.porgcoat.2007.10.002

21 A. Rudawska and E. Jacniacka, Int. J. Adhes. Adhes., 29, $451 \quad$ (2009), https://doi.org/10.1016/j.ijadhadh.2008.09.008

22 F. Hejda, P. Solar and J. Kousal, in Procs. $19^{\text {th }}$ Annual Conference (WDS'10), Prague, June 1-4, 2010, pp. 25-30, https://pdfs.semanticscholar.org/e5a0/e7dc916cfeb7f0b 4a3e24027cf7421d5d5e0.pdf 